\title{
A Competitiveness Index of Soil Tillage and Planting Among Sugarcane Mills and Suppliers: The Benefits of Cost Reduction and High Production Strategies
}

\author{
Fernando Rodrigues de Amorim ${ }^{1}$, Marco Tulio Ospina Patino ${ }^{1} \&$ Alequexandre Galvez de Andrade ${ }^{2}$ \\ ${ }^{1}$ School of Agricultural Engineering (FEAGRI), University of Campinas (UNICAMP), State of São Paulo, Brazil \\ ${ }^{2}$ Federal Institute of São Paulo, State of São Paulo, Brazil \\ Correspondence: Fernando Rodrigues de Amorim, School of Agricultural Engineering (FEAGRI), University of \\ Campinas (UNICAMP), State of São Paulo, Brazil.
}

Received: May 13, 2021

doi:10.5430/ijba.v13n2p39
Accepted: June 29, 2021

Online Published: February 27, 2022

URL: https://doi.org/10.5430/ijba.v13n2p39

\begin{abstract}
Sugarcane mills (SCMs) and sugarcane suppliers (SCSs) use different production systems. To increase competitiveness, these systems use cost reduction, high productivity investment, and technology strategies according to their scale of production, that is, small $(\mathrm{S})$, medium $(\mathrm{M})$, or large $(\mathrm{L})$. The question that arises is: which of the three production scales, among SCMs and SCSs, have the best competitiveness index in activities related to soil tillage and sugarcane planting? The objective of this research was to analyze and compare a competitiveness index built by using the values of four variables: planted area, sugarcane replanted area, cost of soil tillage, and cost of planting. The study was conducted with data corresponding to the 2017/18 harvest season from 31 SCMs and 42 SCSs located in Brazil. In addition, Monte Carlo Simulation was used to analyze the level of certain costs and profits through relative frequency. Small scale suppliers showed the highest productivity and lowest cost in soil tillage, while the medium scale sugarcane mills revealed the smallest sugarcane replanting cycle area and the lowest cost of planting. However, the competitiveness index showed that SCSs are more competitive than SCMs, with both kind of sugarcane producers taking the benefits of using cost reduction and high productivity strategies.
\end{abstract}

Keywords: productivity, reformed area, Monte Carlo simulation, sugar-energy sector, scale of production

\section{Introduction}

Brazilian agricultural commodities are relevant in the economic context, providing a positive economic and social performance for society (through job creation, for example). In this context, sugar (a by-product of sugarcane) has a competitive advantage in exports, being on the rise in the international trade market (Cunha \& Pasqualetto, 2020; Sossa \& Duarte, 2019).

This competitiveness had a significant boost with the modernization of the sugar-energy sector since 1973. This year marked the beginning of a period of incorporation of technologies developed for this sector (Sugarcane Industry Union [UNICA], 2020), and made Brazil one of the most competitive countries in a global context (Sossa \& Duarte, 2019). The sugarcane industry stablished Brazil as the largest sugar producer, with a production of 29 million tons, and at the second place in ethanol production, with 35 billion liters ((Nation Supply Company [CONAB], 2020). These data reflect the production of 620,832 thousand tons of sugarcane (UNICA, 2020).

In this sense, the factors supporting the Brazilian competitiveness in sugarcane production are: the productivity per hectare, which is related to edaphoclimatic factors, the intense technological developments, the cost reduction, and the cultural practices in the sugarcane production cycle, that is soil tillage and sugarcane planting system (Cunha \& Pasqualetto, 2020; Huang, Khan, Perecin, Coelho, \& Zhang, 2020; Sossa \& Duarte, 2019). Furthermore, the improvement of sugarcane varieties (Huang et al., 2020), as well as the practice of soil tillage, are important processes in agricultural production (Cortez, Missio, Barreto, Silva, \& Reis, 2016; De Amorim, Patino, Bartmeyer, \& Santos, 2020).

From another perspective, studies indicate that the competitiveness of the sugar-energy sector is conditioned by the scale of production (Da Silva César, Conejero, Barros Ribeiro, \& Batalha, 2019; De Amorim et al., 2020; Demattê, 
Demattê, Alves, Barbosa, \& Morelli, 2014; Manoel, da Costa Moraes, Santos, \& Neves, 2018; Nacife, Soares, \& Castoldi, 2019; Sossa \& Duarte, 2019), which means productivity per hectare, in addition to the technological contributions, which directly affect competitiveness (De Amorim et al., 2020; Huang et al., 2020; Manoel et al., 2018; Mariotti et al., 2006). Mariotti et al. (2006) and Huang et al. (2020) noted an asymmetry between the innovating through new technologies, productivity, and competitiveness.

However, the production technologies applied in the soil tillage and planting of sugarcane are essential to improving the competitiveness of the productive chain in this sector (De Amorim et al., 2020), as sugar producers with small areas have difficulties in purchasing agricultural machinery (Manoel et al., 2018).

Thus, Demattê et al. (2014) stated that the production costs for this crop vary according to the size of the properties and Da Silva and Marques (2017) indicated that the costs of sugarcane production related to soil tillage increased by $38 \%$, and those for planting increased by 58\%, for suppliers in the Center-South region of Brazil, between 2008 to 2014. These costs increases are higher than the readjustment of $32 \%$ to the value of a sugarcane ton in the same period. In addition, De Amorim et al. (2020) stated that mills are more competitive than suppliers, due to their larger production scale and indicated that there were no studies evaluating the competitiveness between stratified mills and suppliers (Small, Medium, and L) considering agronomic/economic indexes.

In this context, several authors (De Cunha \& Pasqualetto, 2020; de Amorim et al., 2020; Huang et al., 2020; Nacife et al., 2019) stated that it is relevant to seek tools that help in the decision-making process regarding agricultural practices, in order to increase productivity and reduce production costs. This justifies the need to rethink strategies for the stratified groups to remain competitive as for example, the reduction on production costs, and the increase on productivity. Therefore, the objective of this work is to analyze and compare the competitiveness of sugarcane suppliers (SCSs) and sugarcane mills (SCMs), relating to the tillage soil and planting of sugarcane.

\section{Material and Methods}

\subsection{Data Collection}

From the 157 SCMs in activity in the São Paulo state, Brazil, in 2017, 31 SCMs samples were used, thus providing statically significant results. In this state, two important associations must be considered in this context: The Association of Sugarcane Planters in the west zone of the São Paulo State (CANAOESTE) and Guariba Sugarcane Suppliers Association (SOCICANA).

The SCMs were analyzed through their production scale and a structured questionnaire was sent to the sugarcane mills agricultural department that monitored a production between 12,000 to 100,000 sugarcane tons. From that, 42 sugarcane producers were selected.

The choice of this location was intentional, as the representativeness of the state of São Paulo for the sugar-energy sector is evident, representing $54 \%$ of all Brazilian production.

The questionnaire included 15 questions with five alternative answers on the types of soil preparation and planting and their respective production costs.

The suppliers SCSs and SCMs were classified into three groups, premised on the production area with 8,500 to $19,999,20,000$ to 39,999 , and 40,000 to over 70,000 hectares (ha), small, medium, and large groups, respectively. The SCM groups were classified as 112 to 399,400 to 799 , and over 800 ha, small, medium, and large, respectively. All participants consented to the Free and Informed Consent Term - Elaborated based on Resolution $n^{\circ} 466 / 2012$, the Ministry of Health, under the guidelines of the Research Ethics committee from the State University of Campinas (UNICAMP, Campus of Campinas, $\mathrm{n}^{\circ}$ 1.885.220, CAAE 58212716.0.0000.5404).

\subsection{Data Analysis}

For this study, two dimensions were considered: economic and agricultural. These dimensions were considered in the context of the types of soil tillage and planting adopted by SCMs and SCSs, as analyzed through the quantification of partial indexes.

The production strategy, as well as the types of soil, tillage soil, and planting adopted were indicators that allowed the analysis and comparison of the profitability maximization and costs minimization between mills and stratified suppliers (small, medium, and large), according to the chosen production strategy. Moreover, this information can be used to identify the degree(s) of competitiveness between them. Each index has equal weights comprising its entirety, that is, the sum of the components in each index is the same. The indexes were validated by specialists in the sector, using values reported in the literature as parameters for comparison. 
Thus, an equation for the competitiveness index (CI) was created as shown in Equation 1.

$$
\mathrm{CI}=(\mathrm{CIAR}+\mathrm{CIPROD}+\mathrm{CICTMSP}+\mathrm{CICTMP}) / 4
$$

Where:

PROD: productivity (ton/ha); AR: reformed area/ha: percentage of the total planted area; CTMSP: total cost of soil tillage (US\$/ha); CTMP: total cost of soil planting (US\$/ha).

The values of the variables are determined as follows:

\begin{tabular}{llll}
\hline Sub-indicators & $\mathbf{1} \alpha$ & $\mathbf{2}$ & $\mathbf{3} \alpha$ \\
\hline $\mathrm{CI}_{\mathrm{AR}}$ & $\mathrm{CI}_{\mathrm{AR}} \geq 24$ & $13 \leq \mathrm{CI}_{\mathrm{AR}}<24$ & $\mathrm{CI}_{\mathrm{ATR}}<13$ \\
\hline $\mathrm{CI}_{\mathrm{PROD}}$ & $60 \leq \mathrm{CI}_{\mathrm{PROD}} \leq 74$ & $74<\mathrm{CI}_{\mathrm{PROD}} \leq 90$ & $\mathrm{CI}_{\mathrm{PROD}}>90$ \\
\hline $\mathrm{CI}_{\mathrm{CTMSP}}$ & $\mathrm{CI}_{\mathrm{CTMSP}} \geq 374.5$ & $224.7 \leq \mathrm{CI}_{\mathrm{CTMSP}}<374.5$ & $\mathrm{CI}_{\mathrm{CTMSP}}<224.7$ \\
\hline $\mathrm{CI}_{\mathrm{CTMP}}$ & $\mathrm{CI}_{\mathrm{CTMP}} \geq 1123.6$ & $936.3 \leq \mathrm{CI}_{\mathrm{CTMP}}<1123.6$ & $\mathrm{CI}_{\mathrm{CTMP}}<936.3$ \\
\hline $1 \alpha=$ small competitiveness; $2 \alpha=$ mean competitiveness; $3 \alpha=$ high competitiveness;
\end{tabular}

The monetary values in the CTMSP and CTMP were expressed in dollars using an exchange rate of \$USD $1=$ \$BRL 5.38. Based on these indicators, the sugar-energy sector could obtain parameters for analyzing/comparing agricultural strategies through the results obtained from the aforementioned indexes and, thereby, improve its profitability through a comparative analysis 'benchmarking'.

The data were analyzed using descriptive statistics (descriptive measures). The average values of each group were used as indicators in the cost analysis and were obtained using the BioEstat 5.3 software (1995). The normality hypothesis of the data was tested by the Shapiro-Wilk test using a p-value (significance probability obtained from data) of $5 \%$, so as to perform data validation in small sample (4 to 30) units (Shapiro \& Wilk, 1965).

Then, Pearson's linear correlation coefficient was used to verify the associations between the analyzed variables, two by two. This coefficient varies between -1 and 1 , where the closer the value is to 1 (or -1 ), the greater is the linear correlation between the two variables (positive or negative) (Martins \& Domingues, 2014).

To analyze the level of probability of costs and profits through relative frequency, Monte Carlo Simulation (MCS), a free version of the Oracle Crystal Ball software (extension of Excel) was used in order to provide analysis of projections through a stochastic approach. The MCS consists of a numerical method that uses random numbers to solve mathematical problems for which an analytical solution is not known (Souza, Gomes, Alves, \& Gasques, 2020)

The MCS, according to Souza et al. (2020) is used in risk analysis and is performed through models capable of generating possible results through a range of values, in the form of a probability distribution, in which there is inherent uncertainty. In the case of this work, the value used in the lower and upper ranges, to identify the level of probability of costs and profits, was the standard deviation mentioned in the descriptive analysis of the MCS.

The input variables that supported the simulation are referred to 'assumptions' by the Crystal Ball software. All assumptions were made using the normal distribution. The reason for choosing this model is due to the low dispersion of the values presented in the descriptive analysis of the SMC. In this way, the possible values for the variable of interest are simulated, and the average result of the process is obtained through the following way.

$$
a_{m}=\frac{1}{r} \sum_{i=1}^{n} x_{i}
$$

where $\alpha_{m}$ is the average MCS result for the variable of interest $a, x$ consists of the individual result of each simulated iteration, and $n$ is the number of simulations (iterations).

In this article, 50,000 iterations were performed, the maximum number of iterations that the software makes available, which is believed to be a relevant value for the problem of interest.

\section{Results and Discussion}

The descriptive analysis in Table 1 shows that there is great variability in the sizes of the rural properties, especially when comparing the minimum and maximum sizes of the properties and the standard deviation. The results for the 
coefficient of variation show that the group of small suppliers has a high dispersion $(>30 \%)$, small mills have a moderate dispersion (> 20\%), and the other groups have medium to low dispersion (10 to 20\%). As for normality, the probabilities of significance obtained through the data (p-values) are greater than $5 \%$, showing that the data are normal.

The Pearson's correlation coefficient also indicates a moderate positive correlation (0.51) between the size of the properties and the total cost of soil preparation. This fact corroborates the results presented by Demattê et al. (2014), who noted differences in production costs between production scales in Table 1.

Table 1. Planted Area (ha) in sugarcane suppliers (SCS) and sugarcane mills (SCM) with three scales of production small (S), medium (M), and large (L)

\begin{tabular}{lllllll}
\hline & & & & Standard & Coefficient of & p-value \\
\hline SCM-S & Maximum & Average & Minimum & deviation & variation & (Shapiro-Wilk) \\
\hline SCM-M & 15.586 & 11.747 & 8.500 & 2.489 & 21.20 & 0.990 \\
\hline SCM-L & 38.095 & 29.500 & 20.000 & 5.196 & 17.60 & 0.440 \\
\hline SCS-S & 70.000 & 55.535 & 46.795 & 10.029 & 18.10 & 0.270 \\
\hline SCS-M & 390 & 252 & 112 & 91.73 & 36.40 & 0.190 \\
\hline SCS-L & 1300 & 518 & 411 & 82.50 & 15.90 & 0.500 \\
\hline
\end{tabular}

Source: Compiled by the authors.

As for the percentage of sugarcane reformed area, the descriptive analysis in Table 2 showed that there is a wide variation in the reformed area for all groups analyzed, as evidenced by the maximum and minimum values and standard deviation. Corroborating these results, all the coefficients of variation, except for SCM-S, showed values above $30 \%$, thus indicating that the data had high dispersion around the average area of each group.

Regarding normality, only the SCS-S group presented a value of $<5 \%$, whereas the others had normality for the renovated areas. Furthermore, De Amorim et al. (2020) affirmed that groups that reform a smaller percentage of the total area of their properties with sugarcane each year, have a lower production cost per hectare/ton and, consequently, a greater profitability. Thus, no significant positive/negative correlation was found between the reformed area and other variables in Table 2.

Table 2. Reformed Area (\%) in sugarcane suppliers (SCS) and sugarcane mills (SCM) with three scales of production small $(\mathrm{S})$, medium $(\mathrm{M})$, and large $(\mathrm{L})$

\begin{tabular}{lllllll}
\hline & & & & Standard & Coefficient of & p-value \\
\hline SCM-S & Maximum & Average & Minimum & deviation & variation & (Shapiro-Wilk) \\
\hline SCM-M & $24 \%$ & $18 \%$ & $12 \%$ & 0.04 & 24.96 & 0.620 \\
\hline SCM-L & $35 \%$ & $15 \%$ & $4 \%$ & 0.02 & 46.00 & 0.300 \\
\hline SCS-S & $20 \%$ & $14 \%$ & $6 \%$ & 0.05 & 38.00 & 0.640 \\
\hline SCS-M & $23 \%$ & $19 \%$ & $2 \%$ & 0.13 & 65.30 & 0.008 \\
\hline SCS-L & $32 \%$ & $13 \%$ & $5 \%$ & 0.05 & 40.90 & 0.940 \\
\hline
\end{tabular}

Source: Compiled by the authors.

In the descriptive analysis of the total cost of soil tillage, Table 3, the highlight were the large suppliers as they obtained the lowest costs (maximum and minimum). It can also be observed that all groups presented normal data and moderate variation around the total average cost of each group, except for SCS-M (value above 30\%). It can also 
be observed (Table 3) that the costs for suppliers (SCS-S) were similar to the minimum cost values for soil preparation, as mentioned by De Amorim et al. (2020).

Table 3. Cost of soil tillage (US\$) in sugarcane suppliers (SCS) and sugarcane mills (SCM) with three scales of production small $(\mathrm{S})$, medium $(\mathrm{M})$, and large $(\mathrm{L})$

\begin{tabular}{lllllll}
\hline & & & & Standard & Coefficient of & p-value \\
\hline SCM-S & 449.44 & 300.25 & 181.65 & 87.41 & 29.11 & 0.550 \\
\hline SCM-M & 458.80 & 350.56 & 262.17 & 52.81 & 15.10 & 0.230 \\
\hline SCM-L & 449.44 & 333.33 & 262.17 & 70.57 & 21.20 & 0.390 \\
\hline SCS-S & 355.81 & 235.35 & 168.54 & 53.73 & 22.80 & 0.300 \\
\hline SCS-M & 467.79 & 294.43 & 467.79 & 111.41 & 37.80 & 0.300 \\
\hline SCS-L & 346.44 & 243.26 & 159.18 & 56.58 & 23.30 & 0.780 \\
\hline S & & & & & variation & Shapiro-Wilk) \\
\hline
\end{tabular}

Source: Compiled by the authors.

In the descriptive analysis of the total cost of planting in Table 4, there is little variation in the maximum, average, minimum, and standard deviation. The variation coefficient showed low variation in the SCM-S, SCM-M, and SCS-M groups, and the other groups showed medium variation, with normality of the data in all groups for this variable.

When comparing the obtained planting cost results with those in the literature, all groups had maximum values similar to those obtained by Da Silva and Marques (2017) and de Amorim et al. (2020), who used a fixed-rate system. Da Silva and Marques (2017) reported higher values than those found in this study (Table 4).

Table 4. Cost of planting (US\$) in sugarcane suppliers (SCS) and sugarcane mills (SCM) with three scales of production small $(\mathrm{S})$, medium $(\mathrm{M})$, and large $(\mathrm{L})$

\begin{tabular}{lllllll}
\hline & & & & Standard & Coefficient of & p-value \\
\hline SCM-S & $1,020.60$ & 940.39 & 887.64 & 50.17 & 5.34 & (Shapiro-Wilk) \\
\hline SCM-M & $1,155.43$ & 994.88 & 879.03 & 82.59 & 8.30 & 0.620 \\
\hline SCM-L & $1,129.8$ & 952.32 & 823.97 & 130.22 & 13.70 & 0.140 \\
\hline SCS-S & $1,179.8$ & 993.29 & 823.97 & 112.14 & 11.30 & 0.450 \\
\hline SCS-M & $1,104.87$ & 955.76 & 823.97 & 87.23 & 9.13 & 0.930 \\
\hline SCS-L & $1,123.6$ & 934.35 & 823.97 & 97.34 & 10.40 & 0.870
\end{tabular}

Source: Compiled by the authors.

The results referring to productivity showed that the three scales of the suppliers were superior to those of the mills. This shows that the class of suppliers can achieve higher productivity than the class of the mills. This fact was also confirmed by De Amorim et al (2020). The highlight in the standard deviation and variation coefficient was in the group of suppliers (SCM-S), with the least variation among all groups. However, all groups had little dispersion of data around the average.

An increase in sugarcane productivity does not necessarily mean greater profitability (De Amorim et. al. 2020). In this context, Gomes and Bajay (2017) stated that the cost per ton of sugarcane, as related to soil tillage and planting, is correlated with the productivity and average cut of the sugarcane field. Consequently, the smaller the area renovated annually, the greater the competitiveness. Therefore, it is necessary to analyze this relation, from another perspective, for a more effective conclusion (Table 5). 
Table 5. Productivity (ton/ha) in sugarcane suppliers (SCS) and sugarcane mills (SCM) with three scales of production small $(\mathrm{S})$, medium $(\mathrm{M})$, and large $(\mathrm{L})$

\begin{tabular}{lllllll}
\hline & & & & Standard & Coefficient of & p-value \\
\hline Producer & Maximum & Average & Minimum & deviation & variation & (Shapiro-Wilk) \\
\hline SCM-S & 95 & 86.7 & 75 & 9.8 & 11.3 & 0.040 \\
\hline SCM-M & 95 & 82.5 & 65 & 9.10 & 11.00 & 0.009 \\
\hline SCM-L & 85 & 77 & 65 & 10.90 & 14.20 & 0.010 \\
\hline SCS-S & 105.00 & 91.50 & 75.00 & 8.13 & 8.89 & 0.010 \\
\hline SCS-M & 105.00 & 92.50 & 85.00 & 8.86 & 9.58 & 0.020 \\
\hline SCS-L & 105.00 & 87.30 & 75.00 & 9.23 & 10.60 & 0.009 \\
\hline
\end{tabular}

Source: Compiled by the authors.

Thus, the values in Table 6 demonstrated that SCSs and SCMs were more competitive. For instance, they reached the highest value of CI (3) in the variables for productivity, reform area, cost of soil tillage, and cost of planting.

Six SCMs and 19 SCSs reached a CI of 3.0 in productivity. Similar values for SCSs were mentioned by Moreira and Bonizio (2012). Therefore, the results demonstrated that suppliers are more competitive in this regard. However, UNICA (2020) indicated that the 125.2\% increase in sugarcane production in Brazil, between 1992 to 2019, reflects the increase in the area with the culture, and not an increase in production/hectare. Technological inputs are statistically significantly influential on total factor productivity as indicated by an infinite distributed lag model (Souza et al., 2020). Nevertheless, Da Silva César et al (2019) stated that productivity is an essential element in this analysis, as it is one of the critical determinants of competitiveness.

Regarding the reform area, seven sugarcane mills (SCMs) and 10 sugarcane suppliers (SCSs) reached a competitiveness index (CI) of three (3). The results did not show significant differences between the groups. Similar values were mentioned by De Amorim et al. (2020) stating that most of the reformed areas for SCSs and SCMs appeared to occupy between $5 \%$ to $10 \%$ of the total areas, respectively.

The cost of soil tillage for one sugarcane mill and for 21 sugarcane suppliers (SCSs) revealed a CI of three. The superiority of SCSs for this variable is notable. The SCSs had 4.2\% lower performance than that obtained in the work of Da Silva and Marques (2017), and 8.8\% lower performance than the one indicated by De Amorim et al. (2020), based on SCSs using a variable rate system (application of fertilizers and agrochemicals according to each point analyzed by grid or management zone).

As to the cost of planting for 15 SCMs and 18 SCSs, SCSs showed better performance relative to SCMs, as also evidenced by De Amorim et al. (2020). Similar values (referring to SCSs) were mentioned by Moreira and Bonizio (2012).

In addition, 20 sugarcane mills (SCMs) and 23 sugarcane suppliers (SCSs) reached a CI of two (2) in productivity. The greater concentration of both types of sugarcane producers in this index is notable, with a larger proportion for the group SCMs. Similar values for this same range of production in SCSs were mentioned in the works of Da Silva and Marques (2017) and de Amorim et al. (2020) for SCMs. In addition, reform area of 20 SCMs and 25 SCSs reached a CI of 2.0. The better performance of SCSs relative to SCMs is also important to note. According to (Da Silva \& Marques, 2017), the analysis indicates a slow rhythm of sugarcane field renovation, and the adoption of old varieties.

A significant portion of the SCSs (20) is part of this index, meaning the cost of tillage. Nonetheless, most of the costs of planting (21) of SCMs meet this cost range. In this case, the SCMs are less competitive than SCSs. However, regarding the cost of planting (13), the index shows a certain balance in production costs (in percentage) between a significant portion of SCSs (13) and of SCMs (19). 
Table 6. Competitiveness index and the percentage of sugarcane suppliers (SCS) and sugarcane mills (SCM) at the main variables with three scales of production small (S), medium (M), and large (L)

\begin{tabular}{|c|c|c|c|c|}
\hline \multirow[b]{2}{*}{ Description } & \multicolumn{4}{|c|}{ Competitiveness Index = 3} \\
\hline & Productivity & Reform Area & Cost Of Soil Tillage & Cost Of Planting \\
\hline SCS-S & $28.6 \%$ & $7.1 \%$ & $28.6 \%$ & $14.3 \%$ \\
\hline SCS-M & $9.5 \%$ & $7.1 \%$ & $9.5 \%$ & $9.5 \%$ \\
\hline SCS-L & $9.5 \%$ & $9.5 \%$ & $11.9 \%$ & $19.0 \%$ \\
\hline SCM-S & $9.7 \%$ & $3.2 \%$ & $3.2 \%$ & $9.7 \%$ \\
\hline SCM-M & $12.9 \%$ & $16.1 \%$ & $0.0 \%$ & $29.0 \%$ \\
\hline SCM-L & $0.0 \%$ & $3.2 \%$ & $0.0 \%$ & $9.7 \%$ \\
\hline Total SCS & $47.6 \%$ & $23.7 \%$ & $50 \%$ & $42.8 \%$ \\
\hline \multirow[t]{2}{*}{ Total SCM } & $22.6 \%$ & $22.5 \%$ & $3.2 \%$ & $48.4 \%$ \\
\hline & \multicolumn{4}{|c|}{ Competitiveness Index = 2} \\
\hline SCS-S & $21.4 \%$ & $31 \%$ & $19.0 \%$ & $21.4 \%$ \\
\hline SCS-M & $9.5 \%$ & $14.3 \%$ & $9.5 \%$ & $9.5 \%$ \\
\hline SCS-L & $21.4 \%$ & $14.3 \%$ & $19.0 \%$ & $14.3 \%$ \\
\hline SCM-S & $12.9 \%$ & $12.9 \%$ & $12.9 \%$ & $9.7 \%$ \\
\hline SCM-M & $45.2 \%$ & $45.2 \%$ & $41.9 \%$ & $29.0 \%$ \\
\hline SCM-L & $6.4 \%$ & $9.7 \%$ & $12.9 \%$ & $3.2 \%$ \\
\hline Total SCS & $52.3 \%$ & $59.6 \%$ & $47.5 \%$ & $45.2 \%$ \\
\hline \multirow[t]{2}{*}{ Total SCM } & $64.5 \%$ & $67,8 \%$ & $67.7 \%$ & $41.9 \%$ \\
\hline & \multicolumn{4}{|c|}{ Competitiveness Index = 1} \\
\hline SCS-S & $0 \%$ & $9.5 \%$ & $0 \%$ & $11.9 \%$ \\
\hline SCS-M & $0 \%$ & $0 \%$ & $2.4 \%$ & $0 \%$ \\
\hline SCS-L & $0 \%$ & $7.1 \%$ & $0 \%$ & $0 \%$ \\
\hline SCM-S & $0 \%$ & $6.4 \%$ & $3.2 \%$ & $3.2 \%$ \\
\hline SCM-M & $6.4 \%$ & $3.2 \%$ & $22.6 \%$ & $6.4 \%$ \\
\hline SCM-L & $6.4 \%$ & $0 \%$ & $3.2 \%$ & $0 \%$ \\
\hline Total SCS & $0 \%$ & $16.6 \%$ & $2.4 \%$ & $11.9 \%$ \\
\hline Total SCM & $12.8 \%$ & $9.6 \%$ & $29 \%$ & $9.6 \%$ \\
\hline
\end{tabular}

Source: Compiled by the authors.

In relation to the competitiveness index (CI) of one (1) for productivity and reform area, there was no significant shares of SCSs and SCMs. Regarding the cost of tillage and cost of planting, a significant portion of the SCSs and SCMs were in that index.

The results also showed that SCSs are more competitive than SCMs, that is, they fall mostly into the higher-value indexes, 2.75 and 2.50. However, the vast majority of suppliers and mills fall under the 2.50 and 2.25 indexes and a very small portion to the other indexes. There was no significant difference (without stratifying) in the average value of CI between all mills and suppliers in the productivity variable, that is, 2.16 and 2.07, respectively. However, the mills are more competitive in the index referring to the renovation area, at 1.74 and 2.33 , respectively. In respect to the costs of soil preparation, there were also no significant differences between SCMs (2.38) and SCSs (2.33). Therefore, the success of a rural property with sugarcane depends on good planning of activities focused on increasing yield and minimizing (Cunha \& Pasqualetto, 2020; De Amorim et al., 2020). Finally, for planting costs, mills are more competitive than suppliers at 2.45 and 2.03, respectively (Table 7). 
Table 7. Competitiveness index among cultural practices by sugarcane suppliers (SCS) and sugarcane mills (SCM)

\begin{tabular}{lllllll}
\hline DESCRIPTION & CI 2.75 & CI 2.50 & CI 2.25 & CI 2.0 & CI 1.75 & CI 1.50 \\
SCS-S & $9.5 \%$ & $4.8 \%$ & $16.7 \%$ & $14.3 \%$ & $0 \%$ & $6.4 \%$ \\
SCS-M & $4.8 \%$ & $2.4 \%$ & $7.1 \%$ & $4.8 \%$ & $0 \%$ & $0 \%$ \\
SCS-L & $2.4 \%$ & $9.5 \%$ & $14.3 \%$ & $7.1 \%$ & $0 \%$ & $3.2 \%$ \\
SCM-S & $0 \%$ & $6.4 \%$ & $16.1 \%$ & $3.2 \%$ & $0 \%$ & $0 \%$ \\
SCM-M & $0 \%$ & $0 \%$ & $25.8 \%$ & $22.6 \%$ & $6.4 \%$ & $0 \%$ \\
SCM-L & $0 \%$ & $3.2 \%$ & $0 \%$ & $9.7 \%$ & $0 \%$ & $0 \%$ \\
\hline
\end{tabular}

Source: Compiled by the authors.

The relative frequency graph SCS of the simulation regarding competitiveness indexes showed that the range between 2.27 and 2.35 contains the average indexes with a certainty level of $77.5 \%$ (Figure 1a), for suppliers with a 2.32 competitiveness index. Besides, the relative frequency graph SCM indicated that the range between 2.04 and 2.12 contains the average indexes with a certainty level of $76.2 \%$ (Figure 1b), for suppliers with a 2.08 competitiveness index. These percentages were based on the difference in the standard deviation value of 0.04 between the two groups. The coefficients of variation were 15\% (Figure 1a) and 18\% (Figure 1b) both being considered as average dispersion.

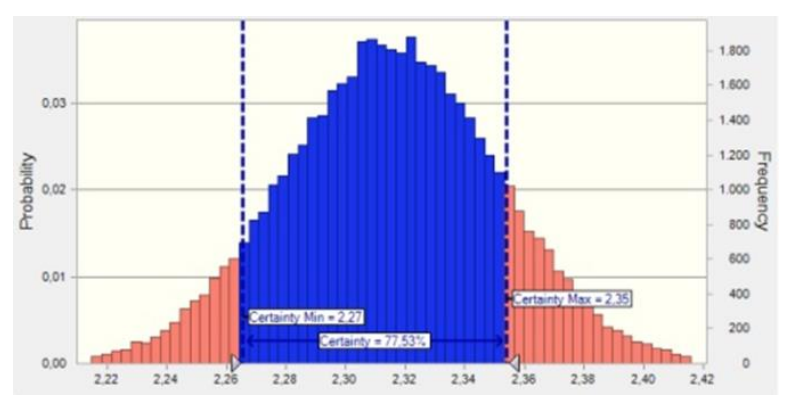

Figure 1a. Relative frequency graph SCS

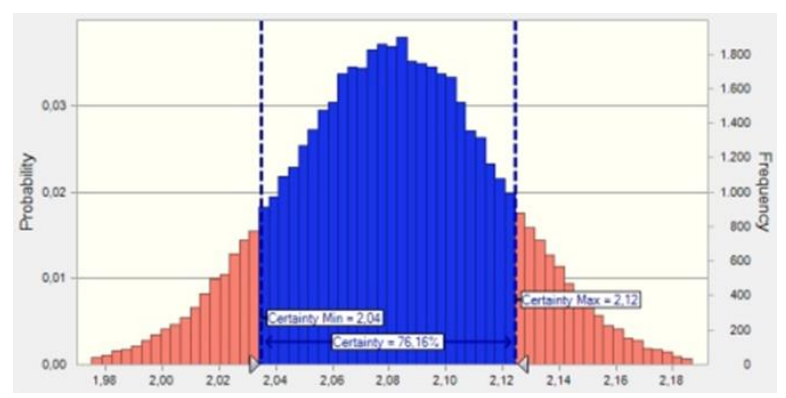

Figure 1b. Relative frequency graph SCM

\section{Conclusion}

The results of this work demonstrated that sugarcane suppliers are more competitive than sugarcane mills in terms of sugarcane productivity per hectare and costs of soil tillage. With respect to the refurbishment area, the mills were more competitive, especially those of medium size that were also more competitive in terms of the cost of sugarcane planting. Analyzing all indexes through the Monte Carlo Simulation, the sugarcane suppliers showed to be slightly superior compared to the sugarcane mills. 
One of the limiting factors of this research is the fact that the proposed competitiveness index considers the same weight for each of the sub-indicators, not considering the weighting or different particularities of each one of them. In this sense, future studies based on the application of fuzzy logic, for example, can incorporate such weightings, and provide competitiveness indexes that better reflect the actual dynamics of sugarcane production. Additional suggestion for future works is for including other variables in the analysis of competitiveness indexes, such as the costs of using fixed or variable rates in soil tillage and sugarcane planting, an average number of cuts in sugarcane fields, and the values of total recovered sugar.

\section{References}

CONAB. (2020). Safra Brasileira de Cana-de-Açúcar. Companhia Nacional de Abastecimento. Retrieved September 30, 2020, from https://www.conab.gov.br/info-agro/safras/cana

Cortez, J. W., Missio, C., Barreto, A. K. G., Silva, M. D. D., \& Reis, G. N. D. (2016). Quality of sugarcane $\begin{array}{llll}\text { mechanized planting. } & \text { Engenharia }\end{array}$ https://doi.org/10.1590/1809-4430-eng.agric.v36n6p1136-1144/2016

Cunha, G. N., \& Pasqualetto, A. (2020). Financial impact of irrigation and nitrogen: topdressing in rural enterprises of sugarcane in Uruaçu, Brazil. International Journal of Business Administration, 11(4), 21. https://doi.org/10.5430/ijba.v11n4p21

Da Silva César, A., Conejero, M. A., Barros Ribeiro, E. C., \& Batalha, M. O. (2019). Competitiveness analysis of "social soybeans" in biodiesel production in Brazil. Renewable Energy, 133(1), 1147-1157. https://doi.org/10.1016/j.renene.2018.08.108

Da Silva, H. T., \& Marques, P. V. (2017). Evolution of production costs in brazilian sugar-energy sector. China-USA Business Review, 16(3), 93-107. https://doi.org/10.17265/1537-1514/2017.03.001

De Amorim, F. R., Patino, M. T. O., Bartmeyer, P. M., \& Santos, D. F. L. (2020). Productivity and profitability of the sugarcane production in the State of Sao Paulo, Brazil. Sugar Tech, 22(4), 596-604. https://doi.org/10.1007/s12355-020-00813-2

Demattê, J. A. M., Demattê, J. L. I., Alves, E. R., Barbosa, R. N., \& Morelli, J. L. (2014). Precision agriculture for sugarcane management: a strategy applied for brazilian conditions. Acta Scientiarum. Agronomy, 36(1), 111. https://doi.org/10.4025/actasciagron.v36i1.17664

Gomes, J., \& Bajay, M. M. (2017). Economicidade da idade de reforma de canaviais. Revista IPecege, 3(3), 9-22. https://doi.org/10.22167/r.ipecege.2017.3.9

Huang, J., Khan, M. T., Perecin, D., Coelho, S. T., \& Zhang, M. (2020). Sugarcane for bioethanol production: Potential of bagasse in Chinese perspective. Renewable and Sustainable Energy Reviews, 133(1), 110-296. https://doi.org/10.1016/j.rser.2020.110296

Manoel, A. A. S., Da Costa Moraes, M. B., Santos, D. F. L., \& Neves, M. F. (2018). Determinants of corporate cash holdings in times of crisis: insights from Brazilian sugarcane industry private firms. International Food and Agribusiness Management Review, 21(2), 201-218. https://doi.org/10.22434/IFAMR2017.0062

Mariotti, J. A., Sopena, R. A., Ullivarri, E., Rago, A. M., Terán, C. H., Collavino, N. G., ... Simón, G. E. (2006). Breeding and sustainable crop management as the basis for competitiveness of sugar cane production in argentina. Sugar Tech, 8(4), 217-223. https://doi.org/10.1007/BF02943559

Martins, G. de A., \& Domingues, O. (2014). Estatística Geral e Aplicada. São Paulo: Atlas.

Moreira, M. G., \& Bonizio, R. C. (2012). Análise comparativa dos custos de cana-de-açúcar: produção independente $\mathrm{x}$ usina de açúcar e álcool. Custos e Agronegócio on Line, 8(2), 84-99. Retrieved from http://www.custoseagronegocioonline.com.br/numero2v8/cana.pdf

Nacife, J. M., Soares, F., \& Castoldi, G. (2019). Cluster analysis referring to rural enterprises of sugarcane Local Productive Arrangement (LPA) in Quirinópolis, Brazil. International Journal of Business Administration, 10(5), 1. https://doi.org/10.5430/ijba.v10n5p1

Shapiro, S. S., \& Wilk, M. B. (1965). An Analysis of Variance Test for Normality (Complete Samples). Biometrika, 52(3/4), 591. https://doi.org/10.2307/2333709

Sossa, C. O., \& Duarte, L. B. (2019). Análise da Competitividade Internacional do Agronegócio Brasileiro no Período de 2003 a 2013. Desenvolvimento Em Questão, 17(49), 59-78. 
https://doi.org/10.21527/2237-6453.2019.49.59-78

Souza, G. da S. E., Gomes, E. G., Alves, E. R. de A., \& Gasques, J. G. (2020). Technological progress in the Brazilian agriculture. Socio-Economic Planning Sciences, $\quad 72(2), \quad$ 1-10. https://doi.org/10.1016/j.seps.2020.100879

UNICA. (2020). Fim de safra no Centro-Sul registra produção recorde de etanol. União da Indústria da Cana-de-Açúcar. $\quad$ Retrieved December $\quad 13, \quad 2020$, from https://unica.com.br/noticias/fim-de-safra-no-centro-sul-registra-producao-recorde-de-etanol/

\section{Copyrights}

Copyright for this article is retained by the author(s), with first publication rights granted to the journal.

This is an open-access article distributed under the terms and conditions of the Creative Commons Attribution license (http://creativecommons.org/licenses/by/4.0/). 